\title{
MicroRNA-124 inhibits cell proliferation and migration by regulating SNAI2 in breast cancer
}

\author{
SHANMEI DU ${ }^{1 *}$, HELOU LI ${ }^{2 *}$, XIAOCHUN SUN ${ }^{3}$, DONGSHENG $\mathrm{LI}^{4}$,

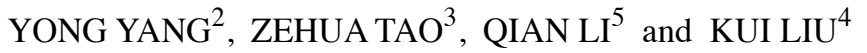

\begin{abstract}
${ }^{1}$ School of Medicine, Southeast University, Nanjing, Jiangsu 210009; ${ }^{2}$ Affiliated Hospital of Taishan Medical College, Tai'an, Shandong 271000; ${ }^{3}$ School of Medicine, Jiangsu University, Zhenjiang, Jiangsu 212013;

${ }^{4}$ The First Hospital of Zibo, Zibo, Shandong 255200; ${ }^{5}$ Zibo Vocational Institute, Zibo, Shandong 255314, P.R. China
\end{abstract}

Received April 22, 2016; Accepted June 4, 2016

DOI: $10.3892 /$ or.2016.5163

\begin{abstract}
MicroRNA (miRNA) is a type of endogenous non-coding RNA implicated in various cellular processes. Studies have shown that miR-124 is involved in the malignant progression of cancer, but little is known concerning its potential role in breast cancer. Therefore, the purpose of this study was to conduct a functional analysis of miR-124 in breast cancer, and to identify its target genes in this disease. To this end, we used quantitative real-time PCR to examine the expression level of miR-124 in breast cancer tissue specimens and cell lines. To study the functional significance of miR-124, we overexpressed miR-124 with miR-124 mimics and observed breast cancer cell proliferation, colony formation, migration, and invasion abilities by in vitro cell culture experiments. Target prediction algorithms and luciferase reporter gene assays were used to identify the target genes of miR-124. We also knocked down miR-124 targets using short hairpin RNA (shRNA) constructs, and observed associated breast cancer cell characteristics by in vitro cell culture experiments. We found that miR-124 expression significantly decreased in breast cancer tissues and cells compared to normal tissues and cells. In addition, cell proliferation, colony formation, migration, and invasion were decreased after overexpression of miR-124 in breast cancer cells. Furthermore, we used several algorithms to identify the snail family zinc finger 2 (SNAI2) as a potential target gene of miR-124. The protein expression level and luciferase activity of the 3'-untranslated region of SNAI2 were significantly decreased in breast cancer cells transfected with miR-124 mimics. Cell proliferation, colony formation, migration, and invasion were also decreased after knockdown of SNAI2 by shRNA. In conclusion, our data suggest that
\end{abstract}

Correspondence to: Dr Kui Liu, The First Hospital of Zibo, 4 Emeishan East Road, Zibo, Shandong 255200, P.R. China E-mail: liukui37190158@163.com

*Contributed equally

Key words: breast cancer, miR-124, proliferation, migration, snail family zinc finger 2
miR-124 expression is decreased in breast cancer and plays an important role as a tumor suppressor gene by targeting SNAI2. These findings may reveal novel perspectives for clinical treatments against breast cancer.

\section{Introduction}

MicroRNAs (miRNAs) are endogenously processed non-coding RNAs that regulate gene expression by blocking translation or decreasing mRNA stability $(1,2)$. Since the discovery of miRNAs in 1993 (3), they have been shown to affect multiple cellular processes (4), and in particular, play significant roles in cancer development and progression (5). miRNAs can function as tumor suppressors or oncogenes, depending on their specific target genes $(6,7)$. For example, miR-145, miR-335, miR-125b-1, miR-126, miR-15a, miR-16-1, miR-31, and miR-335 are all tumor suppressors for specific cancer types (8-11). Recent studies have shown that miRNAs are involved in the malignant progression of breast cancer (12-14). In particular, miR-124 is a brain-enriched miRNA that plays a crucial role in gastrulation and neural development $(15,16)$, and its deregulation is related to carcinogenesis. The expression level of miR-124 is significantly decreased in glioma, medulloblastoma, oral squamous cell carcinoma, hepatocellular carcinoma, and bladder cancer, suggesting that it may function as a tumor suppressor (17-22). However, its function in breast cancer remains unclear. Furthermore, the molecular mechanisms by which it modulates the malignant phenotype of breast cancer cells are not fully understood.

In the present study, we used quantitative real-time PCR (qPCR) to demonstrate that the expression of miR-124 in breast cancer tissue is decreased compared to corresponding adjacent normal tissue. In addition, miR-124 significantly inhibited breast cancer cell proliferation and migration by targeting snail family zinc finger 2 (SNAI2) via its 3'-untranslated region (3'-UTR). Its expression was inversely correlated with SNAI 2 mRNA expression level in breast tissue specimens. Furthermore, knockdown of SNAI2 inhibited the proliferation and migration of breast cancer cells. Together, these data suggest that miR-124 may function as a tumor suppressor that targets SNAI2 to influence the proliferation and migration of breast cancer cells. 


\section{Materials and methods}

Breast tissue specimens. Documented informed consent was obtained from all patients or guardians, and the Ethics Committee of the First Hospital of Zibo (Zibo, Shandong, China) approved all aspects of the study. Breast cancer and adjacent normal tissue samples were obtained from 30 female patients with breast cancer in the Department of Surgery, the First Hospital of Zibo from 2015 to 2016. Both tumor tissues and corresponding adjacent normal tissues were histologically confirmed. Tissue specimens were placed in cryovials, snap-frozen, and stored at $-80^{\circ} \mathrm{C}$ immediately after operation until subsequent use. The protocol for the use of patient samples was approved by the Institutional Review Board of the hospital.

Cell lines and culture. The human breast cancer cell lines MCF-7 and MDA-MB-231, as well as the immortalized human embryonic kidney cell line HEK293T, were obtained from Jiangsu University (Zhenjiang, Jiangsu, China). The human breast cancer cell line BT-474, as well the immortalized breast epithelial cell line MCF-10A, were obtained from the Central Laboratory of the First Hospital of Zibo.MCF-7,MDA-MB-231, and HEK293T cells were cultured in Dulbecco's modified Eagle's medium (DMEM; Gibco-BRL, Carlsbad, CA, USA) with low glucose (L-DMEM) supplemented with 10\% fetal bovine serum (FBS; ExCell Biology, Inc., Shanghai, China). Another breast cancer cell line, BT-474, was maintained in RPMI-1640 (Gibco-BRL) with 10\% FBS. HEK293T cells and the human breast epithelial cell line MCF-10A were cultured in DMEM with $10 \%$ FBS. All of the cells were maintained in a humidified atmosphere of $5 \% \mathrm{CO}_{2}$ and $95 \%$ air at $37^{\circ} \mathrm{C}$.

Transient miRNA transfection. The MCF-7 cell line was selected for transfection of miR-124. miR-124 mimics and negative miRNA mimic controls (NC miR-mimics) were synthesized and purified by GenePharma (Shanghai, China). The sequences are listed in Table I. Briefly, the cells were grown overnight and then transfected with $100 \mathrm{nM}$ miR-124 mimics or NC miR-mimics using Lipofectamine ${ }^{\circledR} 2000$ (Invitrogen; Thermo Fisher Scientific, Waltham, MA, USA) according to the manufacturer's instructions.

Short hairpin RNA transfection. Short hairpin RNA (shRNA) constructs against SNAI2 were from Origene Co. (GenePharma). MCF-7 cells were cultured until 70-80\% confluence was reached. Cells were transfected with shRNA using Lipofectamine ${ }^{\circledR} 2000$ according to the manufacturer's instructions. The level of SNAI2 expression was determined by western blot analysis.

RNA isolation and $q P C R$. Total RNA in tissues and cell lines was isolated with TRIzol reagent (Invitrogen, Carlsbad, CA, USA) according to the manufacturer's instructions. RNA was also isolated with TRIzol reagent from cell lines transfected with miR-124 mimics and NC miR-mimics for 24,48 and $72 \mathrm{~h}$. To measure miR-124 RNA expression, qPCR was performed using a SYBR-Green containing PCR kit (GenePharma). For detection of SNAI2 mRNA, cDNA was synthesized from $1 \mu \mathrm{g}$ total RNA using the reverse transcription kit in accordance
Table I. Sequences of miR-124 mimics and negative miRNA mimic controls.

\begin{tabular}{|c|c|}
\hline Name & Sequence $\left(5^{\prime}-3^{\prime}\right)$ \\
\hline miR-124 & Sense: UAAGGCACGCGGUGAAUGCC \\
\hline mimics & Antisense: CAUUCACCGCGUGCCUUAUU \\
\hline $\begin{array}{l}\text { Mimic } \\
\text { negative } \\
\text { control }\end{array}$ & $\begin{array}{ll}\text { Sense: } & \text { UUCUCCGAACGUGUCACGUTT } \\
\text { Antisense: } & \text { ACGUGACACGUUCGGAGAATT }\end{array}$ \\
\hline
\end{tabular}

Table II. Specific primers for target and control genes.

\begin{tabular}{ll}
\hline Name & \multicolumn{1}{c}{ Sequence (5'-3') } \\
\hline miR-124 & F: ACGTTGTGTAGCTTATCAGACTG \\
& R: AATGGTTGTTCTCCACACTCTC \\
U6 snRNA & F: ATTGGAACGATACAGAGAAGATT \\
& F: GGAACGCTTCACGAATTTG \\
SNAI2 & F: ACATAAGCAGCTGCACTGCG \\
& R: ATGGGTCTGCAGATGAGCCC \\
$\beta$-actin & F: TGGCACCCAGCACAATGAA \\
& R: CTAAGTCATAGTCCGCCTAGAAGCA
\end{tabular}

F, forward; R, reverse; SNAI2, snail family zinc finger 2 .

with the manufacturer's instructions (Thermo Fisher Scientific). Then, qPCR was performed using UltraSYBR Mixture (with ROX) assay kits (CWBio, Beijing, China) according to the manufacturer's instructions. The CFX-96 real-time fluorescence thermal cycler (Bio-Rad, NJ, USA) was used for the quantitative detection of miRNA and mRNA. The relative expression levels of miRNA and mRNA were normalized to the expression of U6 snRNA and $\beta$-actin mRNA, respectively. The expression of each gene was quantified by measuring cycle threshold $(\mathrm{Ct})$ values and normalized using the $2^{-\Delta \mathrm{Ct}}$ or $2^{-\Delta \Delta \mathrm{Ct}}$ Ct method relative to U6 snRNA or $\beta$-actin mRNA. All of the primer sequences are listed in Table II.

Cell proliferation assay. Twenty-four hours after transient transfection with miR-124 mimics or NC miR-mimics or after knockdown of SNAI2, MCF-7 breast cancer cells were harvested and sub-cultured in 96-well plates. Cell proliferation was assessed using thiazolyl blue tetrazolium bromide assay (MTT; Amresco, Radnor, PA, USA) according to the manufacturer's instructions. Briefly, MTT reagent $(20 \mu \mathrm{l})$ was added to each well and incubated at $37^{\circ} \mathrm{C}$ for $4 \mathrm{~h}$. Then, the reagent was removed and dimethyl sulfoxide $(150 \mu \mathrm{l})$ was added to each well. Absorbance at $492 \mathrm{~nm}$ was measured using the FLx800 fluorescence microplate reader (BioTek, Winooski, VT, USA). The experiment was performed in triplicate and repeated three times. The data are summarized as means \pm standard error of the mean (SEM).

Colony formation assay. MCF-7 breast cancer cells were transfected as described above in the presence or knockdown 
of SNAI2, seeded into 12 -well plates $\left(0.3 \times 10^{3}\right.$ cells/well), and incubated for 10 days. Then, cells were fixed and stained, followed by colony counting. The experiment was performed in triplicate, with data summarized as means \pm SEM.

Wound healing assay. MCF-7 breast cancer cells were seeded into 6-well plates, transiently transfected as previously described to overexpress miRNA or knockdown SNAI2, and then allowed to grow until $100 \%$ confluent. Next, the cell layer was scratched through the central axis using a sterile plastic tip, and loose cells were washed away with phosphate-buffered saline. Wound healing was observed and photographed at 0 and $48 \mathrm{~h}$ in three randomly selected microscopic fields for each condition and time-point. The degree of motility $48 \mathrm{~h}$ after confluent cells had been scratched was expressed as the percentage of wound closure calculated as follows: (Distance of cell migration at $48 \mathrm{~h} /$ distance of scratch at $0 \mathrm{~h}$ ) $\times 100 \%$. The experiment was performed in triplicate and data are summarized as means \pm SEM.

Cell migration and invasion assays. The cell migration assay was performed using Transwell inserts (Corning, Blacksburg, VA, USA), and the cell invasion assay was performed with the CytoSelect 24-well cell invasion assay kit (Cell Biolabs, Inc., San Diego, CA, USA) according to the manufacturer's instructions. The cells were transiently transfected as previously described to overexpress miRNA or knockdown SNAI2. Beginning $48 \mathrm{~h}$ after transfection, cells were starved in L-DMEM without FBS for $2 \mathrm{~h}$, and $5 \times 10^{4}$ cells were resuspended in $0.1 \mathrm{ml}$ L-DMEM without FBS and seeded in the upper chamber of a Transwell insert. Then, L-DMEM containing $20 \%$ FBS was added to the lower chamber as a chemoattractant. To measure the effects of miR-124 or SNAI2 on MCF-7 migration and invasion potential, the cells in the upper chamber were cultured for $14 \mathrm{~h}$ at $37^{\circ} \mathrm{C}$ in humidified $5 \% \mathrm{CO}_{2}$. Cells that had migrated to the lower chamber were fixed and stained with $0.1 \%$ crystal violet. Three low-magnification areas (x100) were randomly selected, and the number of migrated or invasive cells was counted. All of the experiments were performed in triplicate, and data are summarized as means \pm SEM.

Western blot analysis. For protein expression analyses, standard western blotting was performed. Whole cell protein lysates were electrophoresed on $10 \%$ sodium dodecyl sulfate-polyacrylamide gels and transferred onto polyvinylidene fluoride membranes (Beyotime Institute of Biotechnology, Shanghai, China). The membranes were blocked in 5\% skimmed milk/Tris-buffered saline (20 mM Tris- $\mathrm{HCl}$ pH 7.4, $150 \mathrm{mM} \mathrm{NaCl}$, with $0.1 \%$ Tween-20; Tris-buffered saline with Tween-20, TBST) at room temperature for $1 \mathrm{~h}$ and incubated with primary antibodies at $4^{\circ} \mathrm{C}$ overnight. The antibodies were anti-SNAI2 (1:1,000) and anti-glyceraldehyde 3-phosphate dehydrogenase $(1: 1,000)$, all purchased from Cell Signaling Technology, Inc. (Boston, MA, USA). The next day, the membranes were washed with TBST, and then incubated with horseradish peroxidase-linked secondary antibody (anti-rabbit IgG, 1:1,000; Cell Signaling Technology, Inc.). The protein bands were developed with enhanced chemiluminescence reagents (Beyotime Institute of Biotechnology).
Dual-luciferase reporter assay. Putative miR-124 binding sites in the 3'-UTR of the SNAI2 mRNA was synthesized and inserted into the $X b a \mathrm{I}$ and FseI sites of the pGL3-control vector (Promega, Madison, WI, USA). These constructs were named pGL3-SNAI2-wt and pGL3-SNAI2-mut. For the reporter assay, $293 \mathrm{~T}$ cells were plated onto 24-well plates and transfected into pGL3-SNAI2-wt or pGL3-SNAI2-mut and pLL3.7-miR-124 or pLL3.7-miR-control vector using Lipofectamine ${ }^{\circledR} 2000$ according to the manufacturer's instructions. The Renilla luciferase vector pRL-SV50 (Promega) was also co-transfected to normalize the differences in transfection efficiency. After transfection for $48 \mathrm{~h}$, cells were harvested and assayed with the Dual-Luciferase Reporter assay system (Promega) according to the manufacturer's instructions. The experiment was performed in triplicate and data are summarized as means \pm SEM.

Statistical analysis. For statistical analyses, mean values \pm SEM were generated from several repeats of each experiment. The P-values were obtained from t-tests with paired or unpaired samples and $\mathrm{P}<0.05$ was considered statistically significant. The correlation between miR-124 and SNAI2 expression was analyzed using Spearman correlation and $\mathrm{P}<0.05$ was considered statistically significant.

\section{Results}

miR-124 is decreased in breast cancer tissues and cells. To investigate the role of miR-124 in the initiation and progression of human breast cancer, we used qPCR to determine miR-124 levels in 30 breast cancer tissues and adjacent normal breast tissues. As shown in Fig. 1A, the expression of miR-124 was significantly reduced in cancer tissues compared to adjacent normal tissues $(\mathrm{P}<0.001)$. We further evaluated the expression levels of miR-124 in breast cancer cell lines, and found that its expression was decreased to varying degrees in the three tested breast cancer cell lines compared to $\mathrm{MCF}-10 \mathrm{~A}(\mathrm{P}<0.001)$, an immortalized breast epithelial cell line (Fig. 1B). These results indicate that the reduced miR-124 expression is a frequent event in human breast cancer tissues and cells, and may play a role in breast carcinoma progression. We selected the MCF-7 breast cancer cell line for subsequent experiments.

miR-124 inhibits breast cancer cell proliferation, colony formation, migration, and invasion. To confirm the function of miR-124, we transfected miR-124 mimics or negative control sequences into MCF-7 breast cancer cells. Transfection efficiency was estimated by fluorescence microscopy $6 \mathrm{~h}$ after transfection, and miR-124 expression was determined by $\mathrm{qPCR}$ at 24,48 and $72 \mathrm{~h}$. The results showed that the miR-124 mimics significantly increased miR-124 RNA expression in these cells (Fig. 2A). The functional analyses showed a significant decrease in cell proliferation (Fig. 2B), colony formation (Fig. 2C), migration (Fig. 2D and E), and invasion (Fig. 2F) in cells transfected with miRNA-124 mimics compared to those transfected with NC-miR mimics $(\mathrm{P}<0.001)$.

SNAI2 is a target gene of miR-124. We performed bioinformatic analyses to identify the target genes of miR-124 
A

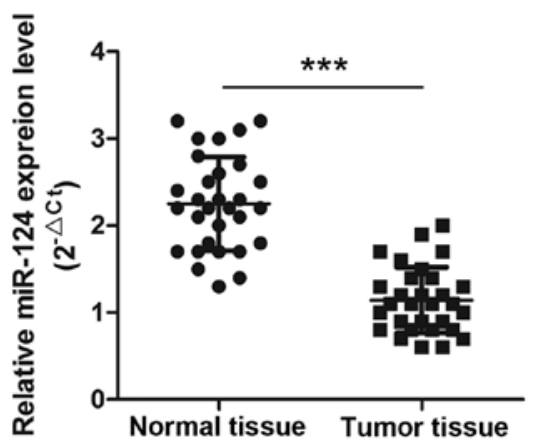

B

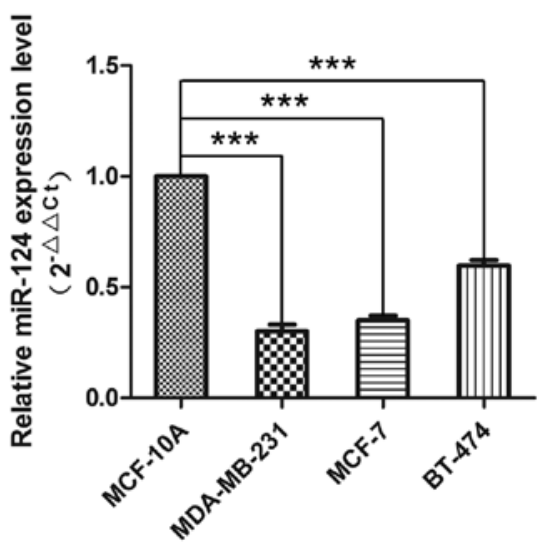

Figure 1. miR-124 levels in breast cancer tissues and breast cancer cell lines. (A) Expression of miR-124 was analyzed by qPCR. The expression level of miR124 was significantly decreased in breast cancer tissues compared to adjacent normal tissues. The graph displays the mean of $2^{-\mathrm{ACt}}$ values $\pm \mathrm{SEM} ;{ }^{* * *} \mathrm{P}<0.001$. (B) The expression level of miR-124 was significantly decreased in breast cancer cell lines compared to MCF-10A cells. The bar graph displays the mean of $2^{-\Delta \Delta C t}$ values $\pm \mathrm{SEM} ;{ }^{* * * *} \mathrm{P}<0.001$.

A

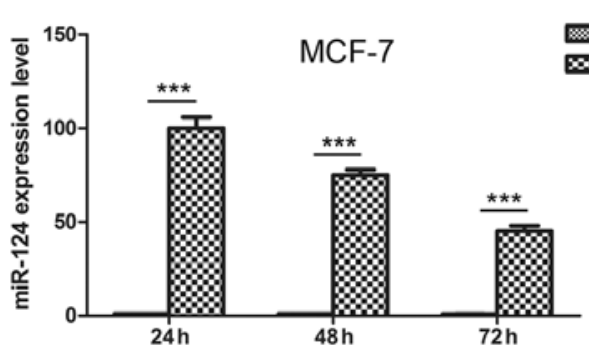

C

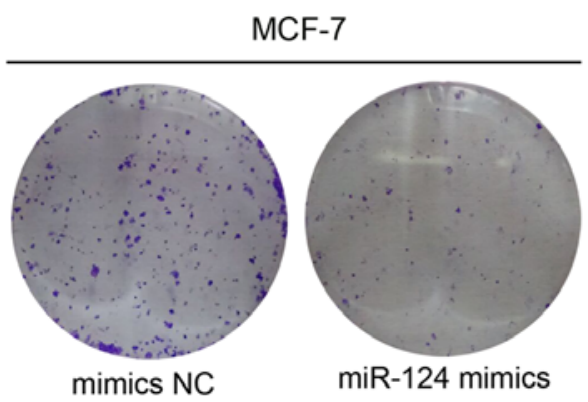

E

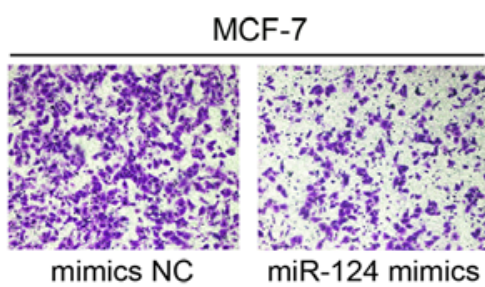

mimics NC

miR-124 mimics

B

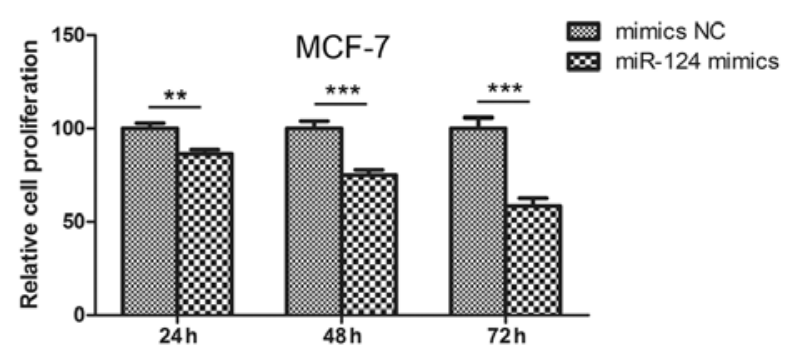

D
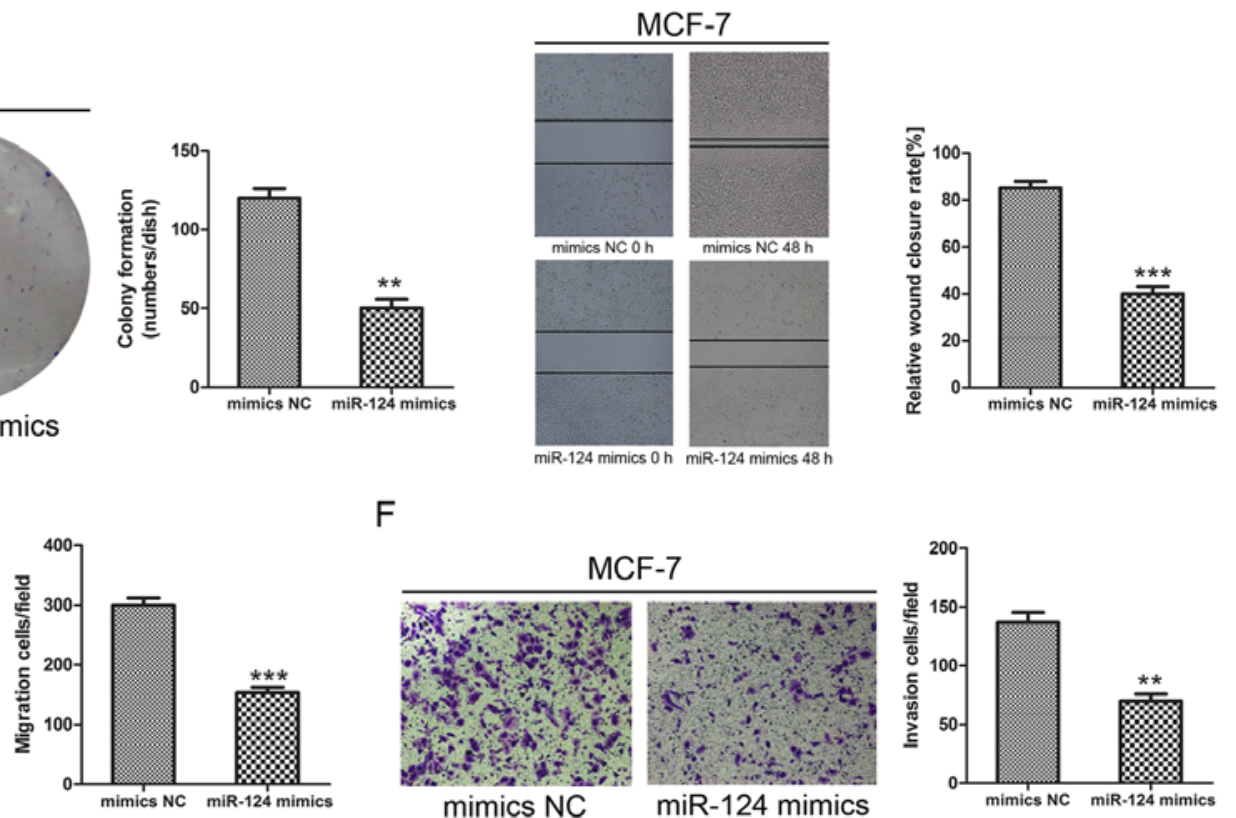

F
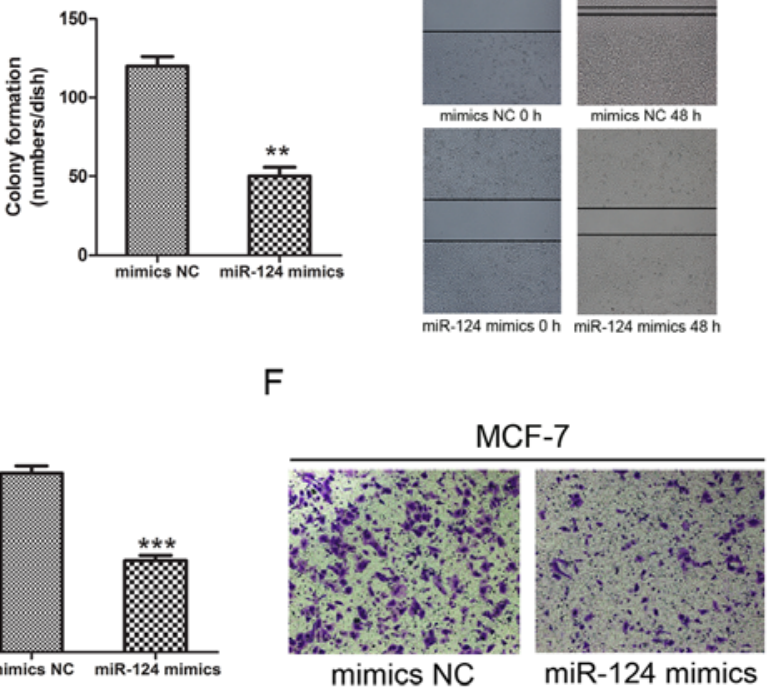

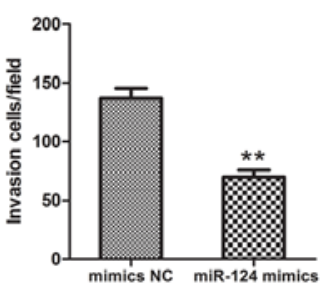

Figure 2. The breast cancer cells were transiently transfected with miR-124 mimics and reduced tumorigenic activity is noted in the breast cancer cells. (A) qPCR was used to investigate miR-124 expression after transfection. miR-124 expression relative to U6 snRNA was significantly increased in response to miR-124 mimics in MCF-7 cells compared to the negative controls (NC-miR mimics). (B-F) miR-124 inhibited cell proliferation (B), cell colony formation (C), cell migration (D and E) and cell invasion (F). Bar graphs display mean \pm SEM of triplicate experiments. ${ }^{* *} \mathrm{P}<0.01,{ }^{* * *} \mathrm{P}<0.001$.

using the miRanda (www.microrna.org) database, and found that SNAI2 is targeted by miR-124. SNAI2 has three potential complimentary binding sites for miR-124 within its 3'-UTR (Fig. 3A). Based on these results, we used qPCR to examine the expression level of SNAI2 mRNA in breast cancer tissue specimens and cell lines. We observed that decreased miR-124 expression is associated with increased SNAI2 mRNA levels $(\mathrm{r}=-0.6694, \mathrm{P}<0.001)$ in patients with breast 
A

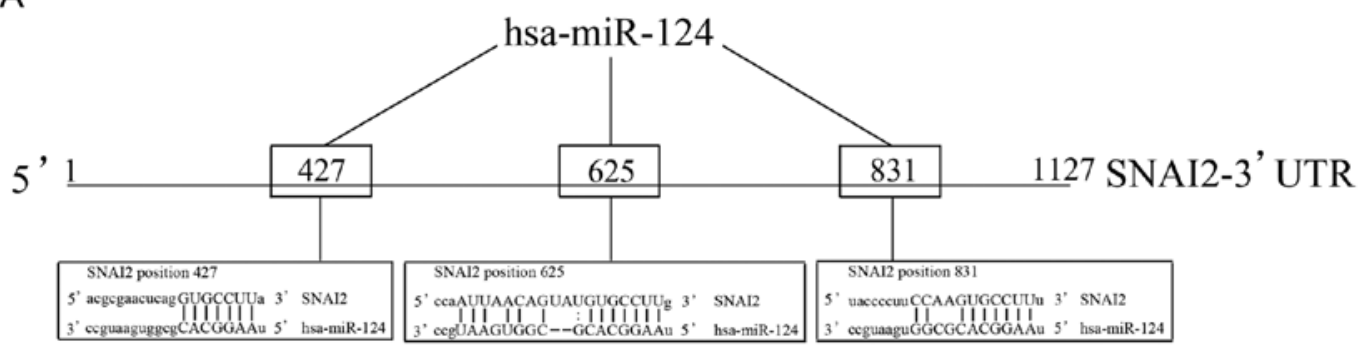

B

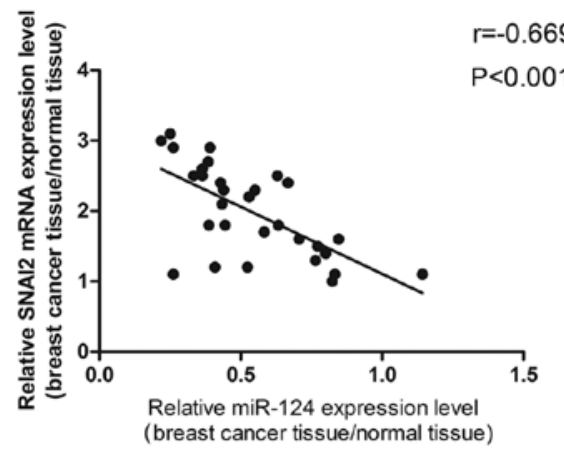

D

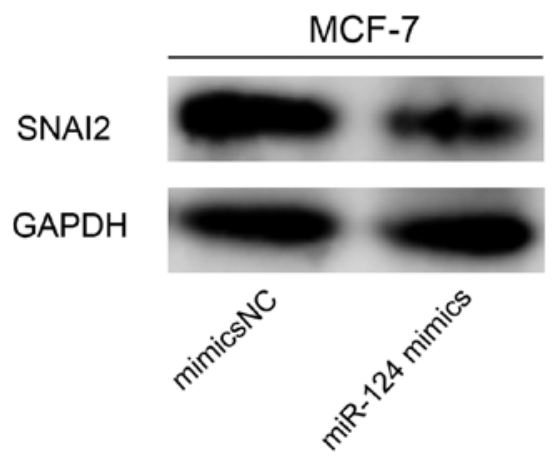

C

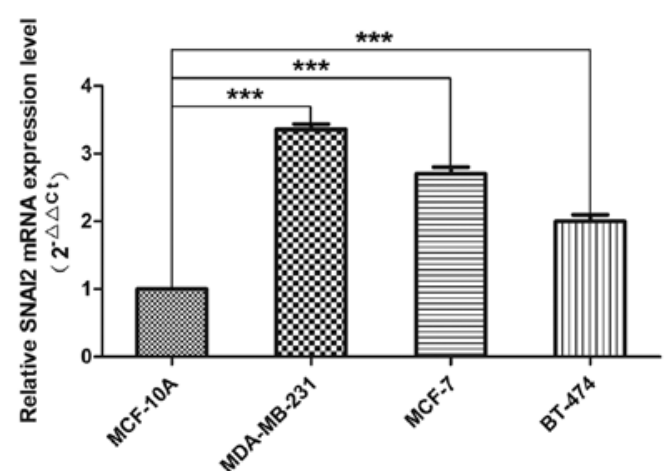

E

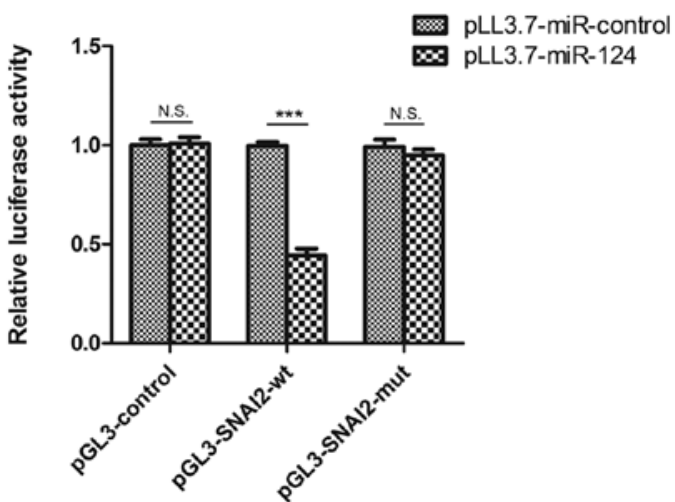

Figure 3. Snail family zinc finger 2 (SNAI2) is a target of miR-21 in breast cancer. (A) Sequence alignment of human miR-124 with the 3'-untranslated region (3'-UTR) of SNAI2. The seed sequence of miR-124 matches the 3'-UTR of SNAI2. (B) Correlation between the ratio of miR-124 expression in the breast cancer tissues compared to adjacent normal tissues and SNAI2. The r-values were calculated by Spearman correlation analysis. (C) The expression level of SNAI2 was significantly increased in breast cancer cell lines compared to MCF-10A cells. The graph displays the mean of $2^{-\Delta \Delta C t}$ value \pm SEM; ${ }^{* * *} \mathrm{P}<0.001$. (D) Western blotting assay of MCF-7 cells transfected with miR-124. (E) Effect of miR-124 on SNAI2 expression as determined by a luciferase reporter assay. The data were normalized by determining the ratio of firefly and Renilla luciferase activities measured at 24-h post-transfection. The results shown represent the mean \pm SEM of triplicate experiments. ${ }^{* * * *} \mathrm{P}<0.001$; n.s., not significant.

cancer (Fig. 3B and C). We performed western blot analysis to assess the effects of miR-124 on SNAI2 expression, and found that SNAI2 protein expression was decreased in MCF-7 cells after treatment with miR-124 mimics compared to the control (Fig. 3D). We used a luciferase assay to determine if miR-124 directly regulates SNAI2, and found that the relative luciferase activities were significantly decreased in the HEK293T cells $(\mathrm{P}<0.001)$ (Fig. 3E). These data show that SNAI2 is a target gene of miR-124.

SNAI2 promotes breast cancer cell proliferation, colony formation, migration, and invasion. To evaluate the effects of SNAI2 on breast cancer cells, we suppressed SNAI2 by shRNA (Fig. 4A). Compared to the negative controls, cell proliferation, colony formation, migration, and invasion were significantly suppressed when cells were treated with shRNA $(\mathrm{P}<0.01, \mathrm{P}<0.001)$ (Fig. 4B-E). These data demonstrate that SNAI2 promotes breast cancer cell proliferation, colony formation, migration, and invasion.

\section{Discussion}

Breast cancer is a common and highly lethal malignancy (23). As many as 1.2 million women worldwide are diagnosed each year, and approximately 500,000 women die annually from this disease (24). The incidence of breast cancer accounts for $7-8 \%$ of the total number of malignant tumors (25). Metastatic progression of breast cancer is a complex and clinically daunting process (26-29). Breast cancer is both genetically and histopathologically heterogeneous. Although many molecular 
A

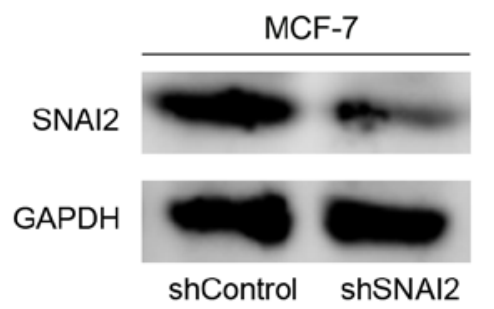

C

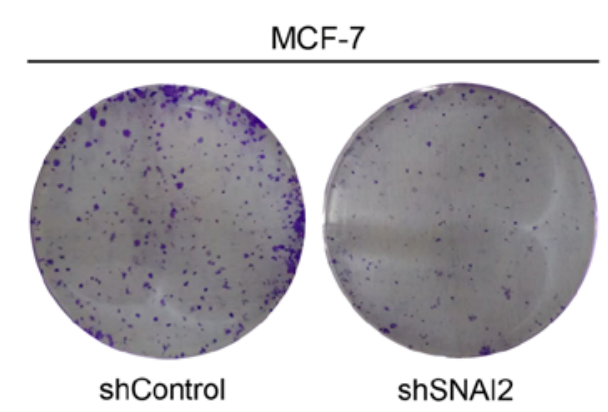

B

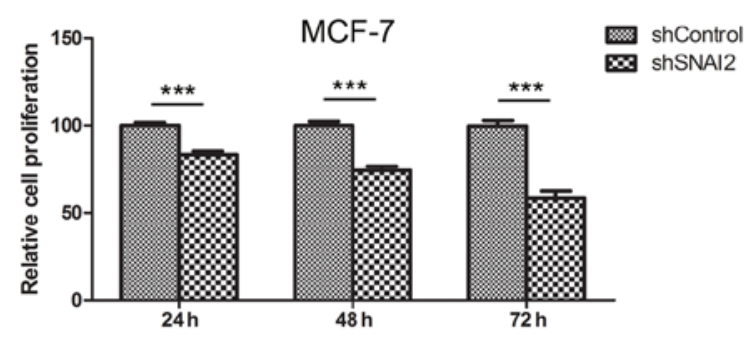

D
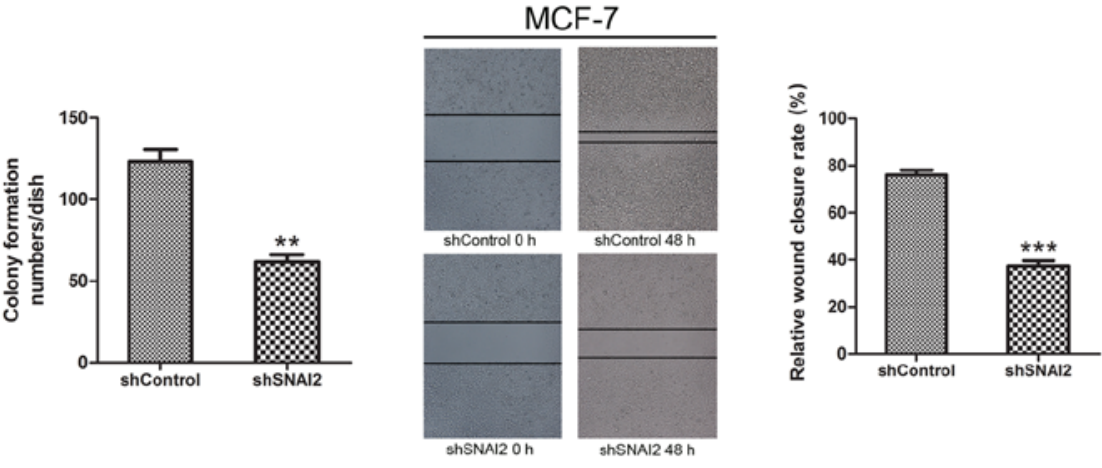

E
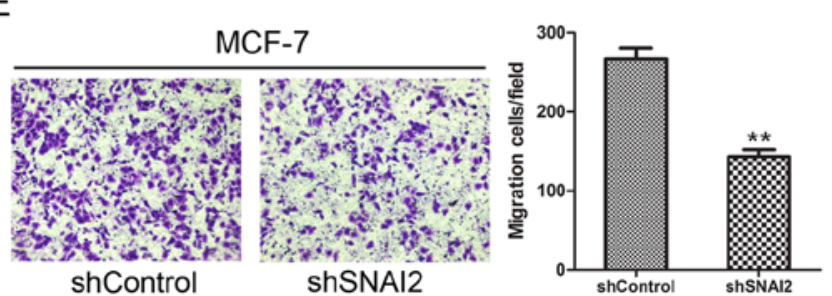

F

Figure 4. Inhibition of snail family zinc finger 2 (SNAI2) reduces tumorigenic activity in breast cancer cells. (A) Western blotting validated the downregulation of SNAI2 after short hairpin RNA (shRNA) knockdown in MCF-7 cells. (B-F) SNAI2 knockdown reduces the proliferation capacity (B), colony formation capacity (C), migration capacity ( $\mathrm{D}$ and $\mathrm{E}$ ) and invasion capacity $(\mathrm{F})$ of MCF-7 cells. Bar graphs display mean $\pm \mathrm{SEM}$ of triplicate experiments. ${ }^{* *} \mathrm{P}<0.01$, ${ }^{* * * *} \mathrm{P}<0.001$.

triggers play a vital role in breast cancer development, the mechanisms underlying this process remain largely unknown. However, an understanding of these mechanisms is crucial for developing effective treatments for this disease.

miRNAs are small noncoding RNAs that usually negatively regulate gene expression by degrading target mRNAs, inhibiting the translation of these mRNAs, or both (30). Many studies have demonstrated that miRNAs can function as oncogenes or tumor suppressors, and are often dysregulated in tumors (31). miRNAs play a vital role in many crucial cellular processes, including apoptosis, differentiation, invasion, and proliferation (32-34). The abnormal expression of miRNA has been reported in many cancers, including breast (35), gastric (36), colorectal (37), and liver cancers (38), as well as leukemia (39) and lymphoma (40). miR-124 has been described as a brain-specific miRNA in mammals, and may play a role in defining and maintaining neuron-specific characteristics $(41,42)$. It has also been reported to function as an important regulator of many human cancers $(43,44)$. In particular, recent studies have indicated that miR-124 targets specific genes to regulate proliferation and migration in breast cancer (45-47).

In this study, we showed that the expression level of miR-124 was significantly decreased in human breast cancer tissues compared to adjacent normal tissues. To determine the role of miR-124 in breast cancer, we transfected miR-124 mimics into breast cancer cells to induce its overexpression. The exogenous overexpression of miR-124 significantly inhibited the cell growth, as indicated by MTT and colony formation assays. Moreover, cell migration and invasion were also significantly decreased by the overexpression of miR-124 in breast cancer cells, as shown by wound healing and Transwell migration assays.

Next, we used online biological software to predict that SNAI2 is a potential target gene of miR-124. SNAI2, a member of the snail family of $\mathrm{C}_{2} \mathrm{H}_{2}$-type zinc-finger transcription factors, promotes epithelial-mesenchymal transition and has antiapoptotic activity (48). These data demonstrate that SNAI2 is a direct target of miR-124, and that miR-124-mediated inhibition of SNAI2 is dependent on a conversed motif in the 3'-UTR of SNAI2. Recent independent studies have shown that the overexpression of SNAI2 alters cell invasion, motility, chemoresistance, metastasis, and poor prognosis in several human cancers (49-52). Furthermore, we showed that the proliferation and migration of breast cancer cells were reduced by inhibiting SNAI2 with shRNA, consistent with the aforementioned conclusion that SNAI2 promotes tumor development. 
In conclusion, our observations suggest that a low level of miR-124 expression may result in the elevated expression of SNAI2. Increased SNAI2 levels would allow breast cancer cells to proliferate and migrate, and would favor tumor progression. Additionally, our results showed that miR-124 inhibited breast cancer cell proliferation and migration by regulating SNAI2 expression. Our findings may advance our understanding of the complex molecular mechanisms underlying the development and maintenance of miR-124-SNAI2 levels that are associated with breast cancer. Based on these data, we suggest that the restoration of miR-124 activity may represent an attractive strategy for breast cancer therapy, and future studies should be focused on this area.

\section{Acknowledgements}

This study was supported by the Natural Scientific Foundation of Shandong Province (grant no. ZR2015PH056).

\section{References}

1. Esquela-Kerscher A and Slack FJ: Oncomirs - microRNAs with a role in cancer. Nat Rev Cancer 6: 259-269, 2006

2. Valencia-Sanchez MA, Liu J, Hannon GJ and Parker R: Control of translation and mRNA degradation by miRNAs and siRNAs. Genes Dev 20: 515-524, 2006.

3. Lee RC, Feinbaum RL and Ambros V: The C. elegans heterochronic gene lin-4 encodes small RNAs with antisense complementarity to lin-14. Cell 75: 843-854, 1993.

4. Iorio MV, Ferracin M, Liu CG, Veronese A, Spizzo R, Sabbioni S Magri E, Pedriali M, Fabbri M, Campiglio M, et al: MicroRNA gene expression deregulation in human breast cancer. Cancer Res 65: 7065-7070, 2005.

5. Croce CM: Causes and consequences of microRNA dysregulation in cancer. Nat Rev Genet 10: 704-714, 2009.

6. Chen CZ: MicroRNAs as oncogenes and tumor suppressors. N Engl J Med 353: 1768-1771, 2005.

7. Kent OA and Mendell JT: A small piece in the cancer puzzle: microRNAs as tumor suppressors and oncogenes. Oncogene 25: 6188-6196, 2006.

8. Tavazoie SF, Alarcón C, Oskarsson T, Padua D, Wang Q, Bos PD, Gerald WL and Massagué J: Endogenous human microRNAs that suppress breast cancer metastasis. Nature 451: 147-152, 2008

9. Sonoki T, Iwanaga E, Mitsuya $\mathrm{H}$ and Asou N: Insertion of microRNA-125b-1, a human homologue of lin-4, into a rearranged immunoglobulin heavy chain gene locus in a patient with precursor B-cell acute lymphoblastic leukemia. Leukemia 19 2009-2010, 2005.

10. Michael MZ, O' Connor SM, van Holst Pellekaan NG, Young GP and James RJ: Reduced accumulation of specific microRNAs in colorectal neoplasia. Mol Cancer Res 1: 882-891, 2003.

11. Calin GA, Dumitru CD, Shimizu M, Bichi R, Zupo S, Noch E, Aldler H, Rattan S, Keating M, Rai K, et al: Frequent deletions and down-regulation of micro-RNA genes miR15 and miRl6 at 13 q14 in chronic lymphocytic leukemia. Proc Natl Acad Sci USA 99: 15524-15529, 2002.

12. Negrini $M$ and Calin GA: Breast cancer metastasis: a microRNA story. Breast Cancer Res 10: 203, 2008.

13. Huang Q, Gumireddy K, Schrier M, le Sage C, Nagel R, Nair S Egan DA, Li A, Huang G, Klein-Szanto AJ, et al: The microRNAs miR-373 and miR-520c promote tumour invasion and metastasis. Nat Cell Biol 10: 202-210, 2008.

14. Ma L, Teruya-Feldstein J and Weinberg RA: Tumour invasion and metastasis initiated by microRNA-10b in breast cancer. Nature 449: 682-688, 2007.

15. Lee MR, Kim JS and Kim KS: miR-124a is important for migratory cell fate transition during gastrulation of human embryonic stem cells. Stem Cells 28: 1550-1559, 2010.

16. Cheng LC, Pastrana E, Tavazoie M and Doetsch F: miR-124 regulates adult neurogenesis in the subventricular zone stem cell niche. Nat Neurosci 12: 399-408, 2009.
17. Xia H, Cheung WK, Ng SS, Jiang X, Jiang S, Sze J, Leung GK, Lu G, Chan DT, Bian XW, et al: Loss of brain-enriched miR-124 microRNA enhances stem-like traits and invasiveness of glioma cells. J Biol Chem 287: 9962-9971, 2012.

18. Hunt S, Jones AV, Hinsley EE, Whawell SA and Lambert DW: MicroRNA-124 suppresses oral squamous cell carcinoma motility by targeting ITGB1. FEBS Lett 585: 187-192, 2011.

19. Furuta M, Kozaki KI, Tanaka S, Arii S, Imoto I and Inazawa J: $m i R-124$ and $m i R-203$ are epigenetically silenced tumor-suppressive microRNAs in hepatocellular carcinoma. Carcinogenesis 31: 766-776, 2010.

20. Zheng F, Liao YJ, Cai MY, Liu YH, Liu TH, Chen SP, Bian XW, Guan XY, Lin MC, Zeng YX, et al: The putative tumour suppressor microRNA-124 modulates hepatocellular carcinoma cell aggressiveness by repressing ROCK2 and EZH2. Gut 61: 278-289, 2012

21. Deng X, Ma L, Wu M, Zhang G, Jin C, Guo Y and Liu R: miR-124 radiosensitizes human glioma cells by targeting CDK4. J Neurooncol 114: 263-274, 2013.

22. Zhang T, Wang J, Zhai X, Li H, Li C and Chang J: MiR-124 retards bladder cancer growth by directly targeting CDK4. Acta Biochim Biophys Sin (Shanghai) 46: 1072-1079, 2014.

23. Torre LA, Bray F, Siegel RL, Ferlay J, Lortet-Tieulent J and Jemal A: Global cancer statistics, 2012. CA Cancer J Clin 65: 87-108, 2015

24. Justo N, Wilking N, Jönsson B, Luciani S and Cazap E: A review of breast cancer care and outcomes in Latin America. Oncologist 18: 248-256, 2013.

25. Key TJ, Verkasalo PK and Banks E: Epidemiology of breast cancer. Lancet Oncol 2: 133-140, 2001.

26. Chiang AC and Massagué J: Molecular basis of metastasis. N Engl J Med 359: 2814-2823, 2008.

27. Talmadge JE and Fidler IJ: AACR centennial series: the biology of cancer metastasis: historical perspective. Cancer Res 70: 5649-5669, 2010

28. Hanahan D and Weinberg RA: Hallmarks of cancer: the next generation. Cell 144: 646-674, 2011.

29. Valastyan S and Weinberg RA: MicroRNAs: Crucial multi-tasking components in the complex circuitry of tumor metastasis. Cell Cycle 8: 3506-3512, 2009.

30. Bartel DP: MicroRNAs: target recognition and regulatory functions. Cell 136: 215-233, 2009.

31. Slack FJ and Weidhaas JB: MicroRNA in cancer prognosis. $\mathrm{N}$ Engl J Med 359: 2720-2722, 2008.

32. Leskelä S, Leandro-García LJ, Mendiola M, Barriuso J, Inglada-Pérez L, Muñoz I, Martínez-Delgado B, Redondo A, de Santiago J, Robledo M, et al: The miR-200 family controls beta-tubulin III expression and is associated with paclitaxel-based treatment response and progression-free survival in ovarian cancer patients. Endocr Relat Cancer 18: 85-95, 2010.

33. Frank D, Gantenberg J, Boomgaarden I, Kuhn C, Will R, Jarr KU, Eden M, Kramer K, Luedde M, Mairbäurl H, et al: MicroRNA-20a inhibits stress-induced cardiomyocyte apoptosis involving its novel target Egln3/PHD3. J Mol Cell Cardiol 52: 711-717, 2012.

34. Dill H, Linder B, Fehr A and Fischer U: Intronic miR-26b controls neuronal differentiation by repressing its host transcript, ctdsp2. Genes Dev 26: 25-30, 2012.

35. Tang H, Liu P, Yang L, Xie X, Ye F, Wu M, Liu X, Chen B, Zhang $\mathrm{L}$ and $\mathrm{X}$ ie $\mathrm{X}$ : miR-185 suppresses tumor proliferation by directly targeting E2F6 and DNMT1 and indirectly upregulating BRCA1 in triple-negative breast cancer. Mol Cancer Ther 13: 3185-3197, 2014

36. Tang H, Deng M, Tang Y, Xie X, Guo J, Kong Y, Ye F, Su Q and Xie X: miR-200b and miR-200c as prognostic factors and mediators of gastric cancer cell progression. Clin Cancer Res 19: 5602-5612, 2013

37. Sun Y, Shen S, Tang H, Xiang J, Peng Y, Tang A, Li N, Zhou W, Wang Z, Zhang D, et al: miR-429 identified by dynamic transcriptome analysis is a new candidate biomarker for colorectal cancer prognosis. OMICS 18: 54-64, 2014.

38. Giordano S and Columbano A: MicroRNAs: new tools for diagnosis, prognosis, and therapy in hepatocellular carcinoma? Hepatology 57: 840-847, 2013.

39. Jiang X, Huang H, Li Z, He C, Li Y, Chen P, Gurbuxani S, Arnovitz S,Hong GM,Price C, etal: MiR-495 is a tumor-suppressor microRNA down-regulated in MLL-rearranged leukemia. Proc Natl Acad Sci USA 109: 19397-19402, 2012.

40. Ralfkiaer U, Hagedorn PH, Bangsgaard N, Løvendorf MB, Ahler CB, Svensson L, Kopp KL, Vennegaard MT, Lauenborg B, Zibert JR, et al: Diagnostic microRNA profiling in cutaneous T-cell lymphoma (CTCL). Blood 118: 5891-5900, 2011. 
41. Makeyev EV, Zhang J, Carrasco MA and Maniatis T: The MicroRNA miR-124 promotes neuronal differentiation by triggering brain-specific alternative pre-mRNA splicing. Mol Cell 27: 435-448, 2007.

42. Cao X, Pfaff SL and Gage FH: A functional study of miR-124 in the developing neural tube. Genes Dev 21: 531-536, 2007.

43. Taniguchi K, Sugito N, Kumazaki M, Shinohara H, Yamada N, Nakagawa Y, Ito Y, Otsuki Y, Uno B, Uchiyama K, et al: MicroRNA-124 inhibits cancer cell growth through PTB1/PKM1/PKM2 feedback cascade in colorectal cancer. Cancer Lett 363: 17-27, 2015.

44. Sun Y, Ai X, Shen S and Lu S: NF-кB-mediated miR-124 suppresses metastasis of non-small-cell lung cancer by targeting MYO10. Oncotarget 6: 8244-8254, 2015.

45. Han ZB, Yang Z, Chi Y, Zhang L, Wang Y, Ji Y, Wang J, Zhao $\mathrm{H}$ and Han ZC: MicroRNA-124 suppresses breast cancer cell growth and motility by targeting CD151. Cell Physiol Biochem 31: 823-832, 2013.

46. Li L, Luo J, Wang B, Wang D, Xie X, Yuan L, Guo J, Xi S, Gao J, Lin X, et al: Microrna-124 targets flotillin-1 to regulate proliferation and migration in breast cancer. Mol Cancer 12: 163, 2013.

47. Li W, Zang W, Liu P, Wang Y, Du Y, Chen X, Deng M, Sun W, Wang L, Zhao G, et al: MicroRNA-124 inhibits cellular proliferation and invasion by targeting Ets-1 in breast cancer. Tumour Biol 35: 10897-10904, 2014.
48. Casas E, Kim J, Bendesky A, Ohno-Machado L, Wolfe CJ and Yang J: Snail2 is an essential mediator of Twist1-induced epithelial mesenchymal transition and metastasis. Cancer Res 71: 245-254, 2011

49. Katafiasz D, Smith LM and Wahl JK III: Slug (SNAI2) expression in oral SCC cells results in altered cell-cell adhesion and increased motility. Cell Adhes Migr 5: 315-322, 2011.

50. Kurrey NK, Jalgaonkar SP, Joglekar AV, Ghanate AD, Chaskar PD, Doiphode RY and Bapat SA: Snail and slug mediate radioresistance and chemoresistance by antagonizing p53-mediated apoptosis and acquiring a stem-like phenotype in ovarian cancer cells. Stem Cells 27: 2059-2068, 2009.

51. Tang P, Yu Z, Zhang K, Wang Y, Ma Z, Zhang S, Chen D and Zhou Y: Slug down-regulation by RNA interference inhibits invasion growth in human esophageal squamous cell carcinoma. BMC Gastroenterol 11: 60, 2011.

52. Wang C, Liu X, Huang H, Ma H, Cai W, Hou J, Huang L, Dai Y, Yu T and Zhou X: Deregulation of Snai2 is associated with metastasis and poor prognosis in tongue squamous cell carcinoma. Int J Cancer 130: 2249-2258, 2012. 